TRADITION VS CHANGE: EVALUATING THE CURRENCY OF SOME TRADITIONAL CHINESE VALUES IN TODAY'S BUSINESS ENVIRONMENT.

Dr Mike Willis

Associate Professor

University of Ballarat

37 King Street South

Ballarat 3350

Victoria

Australia

m.willis@ballarat.edu.au

Journal of International Consumer Marketing, paper 138

FINAL

MAY

EMAILED

EXECUTIVE SUMMARY AT END, ABSTRACT AT BEGINNING

Abstract

Is tradition dead in China? - or, at least, are traditional values dead in a China which has moved progressively into a globalized society and market orientation? This is the question raised in this paper which assessed hw a range of traditional values were conceptualised by a younger generation of Chinese managers who now live and work in a variety of worlds - global, local, international and traditional. What was found that traditional values still remained used and relevant in China, but they had now tended to develop a harder and more westernised edge - sharper, tougher, and more ruthless. Values which were once intuitive and almost innate now tended to be measured and compartmentalised. For example, the value of face - as a traditional value - was still important but was now more than likely a value to be treated as an almost measurable aspect of behaviour. 


\section{TRADITION VS CHANGE: EVALUATING THE CURRENCY OF SOME TRADITIONAL CHINESE VALUES IN TODAY'S BUSINESS ENVIRONMENT.}

\section{INTRODUCTION.}

For many years scholars and business people have emphasised the importance of a range of traditional Chinese values in the conduct of business activities in China, and in particular in the formation and maintenance of strategic alliances using aspects of guanxi behaviour (which can be defined as being relationships based on a deep sense of mutual obligation).

The aim of this paper is to assess how relevant some of these traditional values are amongst the younger generation (25-35) of Chinee business people.

Do values such as face, empathy, trust (in a Chinese sense), respect, balance and moderation - and indeed, guanxi itself - really matter anymore in China? Or are they relics of a Confucian past, replaced by internationalised and often western derived values?

Using qualitative data collected over a period of four years (and then updated in 2007) this paper seeks to find out how relevant and valid a these values are in a society and context of an emerging international superpower.

The importance of this paper is that it considers the current relevance of a range of traditional values amongst the younger generation of Chinese people who increasingly are taking over many Chinese businesses and associated activities. These are the people who will sit across the desk in negotiations, and who will manage joint ventures and similar activities and programs in China. They are the new China in a wide variety of ways. The paper considers their views about a range of traditional 
values - and also makes some closing comments about how the findings might be of relevance to foreigners doing business in China with this new and emerging elite.

\section{LITERATURE BACKGROUND.}

Chinese traditional cultural values have been much researched in terms of strategic alliances and overall foreign market entry into China - for example, by Morgan and Hunt (1994), Wong and Leung (2001), and others as cited below. Some key concepts (which are tested in this study) are as follows:-

Trust: The establishment and maintenance of trust between staff from the two sides of an alliance has been cited as being of importance to alliance success in a range of situations in China (Morgan and Hunt, 1994; Rondinello and Roehrig, 1994). Trust can be viewed as the basic foundation stone of a successful business relationship, especially if it is encompassed in a guanxi relationship situation and context (Huang and Dastmalchian, (2006). Research has indicated that in China, trust has a range of affective and cognitive aspects and components (Wong and Leung, 2001). It can be of considerable depth and may last for some years - even many years. If one trusts a business - or indeed social - partner, the basis is set for the undertaking of a range of activities and projects in a climate of relative security and certainty that the two sides in the relationship will look after each other. Trust can be developed over a very short period of time if the environment and the chemistry between the two or more people are felt to be "right", or it can take a considerable period of time - or it may never develop at all. It is a concept, a value, which is both definable and somewhat elusive (Osland, 1998; Wong and Leung, 2001). Trust as a concept tends to be most applicable at the personal level, that is, between two or more key people in a business, private or social context (Wong and Leung, 2001), yet it also seems to have less personalised dimensions, in that it can be applied to products, services, brands or institutions (Morgan and Hunt, 1994): but the specific nature of trust in a range of situations, contexts and environments is not very clear from research which has tended to focus on trust in a guanxi, personal network or relationship context. (It can also be suggested that trust can be exercised outside a guanxi relationship which, by 
definition, tends to be deep, binding and specifically related to mutual beneficial aspects - but the paring down of the definitions of trust inside and outside guanxi relationships is not very clear in research, although Wong and Leung, 2001, do discuss the nature of trust to some degree, emphasising its complexity). Even so, it remains pivotal to success in China - at least according to research which has tended to focus on middle aged and often pre 2005 China based (and foreign) respondents: it therefore remains unclear whether trust - in its deepest and most intangible form remains at all applicable to today's Chinese community, especially of the younger generation.

Balance: A sense of balance in an alliance has also been noted as being particular importance to its success - for example as discussed by Morgan and Hunt (1994), Pang (1998), Ying (2000), Wong and Leung (2001), and Hutchings (2002). Emanating from deep with Chinese Confucian and daoist philosophy, balance has been described as a perception of a natural and desirable world order, where all is in balance, and where each aspect of the world is also in a balance with all other aspects of the world - including in business. Often related to the concept of harmony, balance as applied to business has been considered to be a state where key business partners feel that there is a degree of fairness, equity, equality, and - balance, in their relationship and in the more tangible aspects of how the business is conducted and managed (Morgan and Hunt, 1994). Balance, in this context, is achieved when each side feels that there is a fundamental sense of unity, equality and integration in their business (Wong and Leung, 2001). Yet balance remains one of the more discursive and elusive of Chinese values, easy to discuss in vague terms but often hard to pin down with any degree of specific certainty (Willis, 2004). Yet it is clear from research that it relates to an affective and sometimes tangible sense of the world (and parts therein,) being in balance, harmony and equilibrium. Certainly, writers such as Wong and Leung (2001), have emphasised its power, importance and historical and - in 2001 - current value and importance. It may be complex and at times vague, but the Chinese traditional sense of balance is also important and powerful. Whether this value holds any real standing amongst today’s younger community also remains a rather moot question. Or has it been replaced or even augmented by more specific, measurable and tangible concepts? 
Moderation: In the literature the concept of moderation has tended to be linked to cross cultural behaviour (“one should be moderate in behaviour in China”), as noted by Creel (1953); Punnet and Yu (1991); Xu (1991); Child (1994); and March (1997). Moderation has a range of strands or aspects in China (Ma, 2006). Ideally, in business and social life, one should “moderate” one's behaviour so that one is discrete, careful, aware of other people's feelings, and considered at all times. In the actual nature and operation of a business, one should also tend to opt for a moderate path - that is, adopting a tried and true "middle" path of managing the business. A cautious and often derivative middle path is often considered best (Creel, 1953). Risk should be carefully considered: one should always try to opt for a position of care, moderation, and should not stand out from others too much: a moderate path is discrete and innately conservative. Therefore, moderation in behaviour and business orientation is often cited as a key and quite complex aspect of Chinese culture and behaviour. However, the nature of how "moderation", as a term, has been applied in any specific context and situation does depend on what is considered to be "moderate" at any point in time in China. Moderate behaviour in Shanghai, for example, may be considered to be rather different than what is considered to be a prudent middle path in western china, where one might expect people to be more traditional, careful and circumspect. Similarly, a business might have a strong brand image and striking position on a main street in Shanghai (often with bright signage and lighting) and this would be considered moderate because it replicates what others are doing - whereas in another part of China it might be considered to be rather "over the top" or out of place, in which case it would not be considered moderate at all. Nevertheless, researchers have tended to agree that moderation, as a value, still tends to apply in China. Like some traditional values, it may be somewhat opaque but it still has a strong sense of being a core value: moderation, in behaviour, with peers, and in life is a key aspect of behaviour in traditional Chinese thought and action. It might vary from place to place but as a concept it has been considered at the heart of cultural values across China (Creel, 1953 - but also, Wong and Leung writing many years later - 2001). However, it has not been tested as a value amongst much younger people in recent years and situations. In a society where more and more people seem to want to stand out from the crowd, perhaps moderation has died away, to be replaced by a more adventurous, and risk taking mentality in which it is considered good to be different and valuable to stand out from others. 
Face. This concept has also been discussed in the literature in some detail (for example by Bourdieu, 1977; Laaksonen, 1988; Barne, 1999; Willis, 2004). It is often linked to guanxi behaviour. Face is often viewed as a key aspect of business success in China, yet it is rarely discussed in complexity or detail - rather it is linked to observations about the need to be polite, show respect and behave with decorum in China. Perhaps like balance, it remains at once easily explained and somewhat impenetrable - yet face, per se, is also powerful and almost overriding as a value in traditional China: to save face is a key aspect of life, particularly in business (Lee, 2005). Face is achieved when one has a situation; environment, circumstance and set of relationships which makes one feel valued, comfortable, at ease, respected and not on guard. "I have a sense of face when I know I am respected and valued" - this is a common way of describing this value. Like all of the values described in this section of this paper, face is linked to other values such as balance, moderation, respect and guanxi relationships, yet it is also a value which can be discussed on its own (Yang and Lee, 2002). Has face as a concept and associated value been reconfigured by today’s younger and seemingly more extrovert generation? Does it still matter at all?

Empathy has been cited in the cross-cultural business literature as being of some importance but has tended to be somewhat generalised in the literature. Neverthless, according to authors such as Eberhard (1971); Shenkar (1991), Tu (1995), and Wong and Leung (2001), it is considered important to have a high degree of empathy between key people in a business venture. This could be said of any business association anywhere in the world, but in China, empathy has a deeper and more meaningful value - it relates to a deep, rich, and almost intangible sense that the key people involved in a business venture can trust each other no matter what. In a guanxi relationship, empathy is part of the deep emotional platform which forms the basis upon which people develop a long term and deeply trusted relationship with each other. Empathy means that the two or more people have a sense of trust, understanding, openness, and a belief that here is a kind of innate and even unspoken ease with each other (Eberhard, 1971). Empathy has been described by some as being pivotal to business success in China. (Tu, 1995; Hoon - Halbauer, 1999, Wong and Leung, 2001). If there is no genuine and deep (and almost intuitive) empathy between key people it is hard to undertake business in a climate of honestly, certainty, 
confidence and success (Wong and Leung, 2001). Again, while it might be possible to argue that empathy has a variety of complexities, as it is a deep and affective value within traditional society, it is also a key and pivotal aspect of behaviour in traditional China: empathy is that which makes it possible for people to form a bond which enables them to undertake a range of activities within an environment of trust and sincerity, respect and commitment (Wong and Leung, 2001).

Stability: Some authors such as Wee (1994, Tu, 1995, Hofstede, 2001, Wong and Leung, 2001) have noted that the Chinese have a propensity for a stable, predictable, organised and structured world and associated business environment, and that this is also desirable in a cross cultural business context and setting. A stable world is at once predictable and in balance, in harmony and operating according to the laws of nature - yet stability may also have more recent aspects such as the turbulence which as surrounded China's development of much of the $20^{\text {th }}$ century. A stable world is one in which people can settle, have families, and prosper and do business - and not all of these concepts emanate from the world of tradition, myth and legends. Yet whether younger people still desire such as stable, moderate, and organised view of the world is hard to identify on the he basis of existing research. Or do they now have a penchant for creative, innovative and dynamic change?

Time: The concept and applicability of time orientation has also been noted by researchers such as Bond (1992); MacInnes (1993); Panagariya (1997), Hofstede (2001), Wong and Leung (2001), and Hung (2004). Chinese people have been described to have a more flexible sense of time than in some western countries. Time may speed up and slow down depending on situation and circumstance. For example, if one trusts another, time tends to have a sense of speed - "we can do this business now" - but if there is a lack of trust, time may become noticeably sluggish and frustrating ("let us meet again and again, no need to hurry”). Whereas one may suggest that time in the west has a certain degree of what perhaps can be termed specific identifiably (that is, time is perceived as a tangible concept - measured on a clock, for example), in China, time is related to culture, context, relationship, issue and perception. Time is also the servant of the context and situation - for example, in China, one might find that a business meeting can take as long as it needs to take to 
get the business done, whereas in the west it may go for a predetermined period of time, for example, two hours. .

Group orientation in Chinese traditional society has also been cited as a key aspect of society (Hofstede, 2001), and the term relates to the propensity for Chinese people to conceptualise the role, function and view of the individual in a group context. In this context, the group is more important than the individual and the individual should at all timers subsume themselves to the view of the group as a whole. Group orientation has been linked to traditional cultural behaviour emanating not just from Confucian and Taoist times but from the more over riding cultural fabric of a society in which the individual tended to be part of a family, village and wider network of communities (Eberhard, 1971).

Guanxi has been researched by all of the authors cited above, and is a complex and wide ranging term which refers to the relationship formed between two or more people on the basis of shared responsibility, mutual benefit and shared gain - such relationships are deep and powerful, enduring and complex (Wong and Maher, 1998, Lin and Miller, 2003). All of the above concepts can help to establish a sense of guanxi amongst people. These relationships are different to the notion of a "close relationship" in the west because of the strong, obligatory and defined sense of mutual obligation which places these relationships closer to what one might term a "family relationship”. In a genuine guanxi relationship, one is expected to look after the other person. One has responsibilities and obligations, and one expects these to be returned. A guanxi relationship can provide a deep and abiding platform for business to be undertaken in a climate of deep understanding and sense of empathy and trust (Fang and Ghauri, 2001). The concept of guanxi relationships may have its roots deep within Chinese traditional culture, and may emanate from village times when networks of relationships formed the fabric which bound a traditional village community together over time (Creel, 1953). In recent times, - that is, over the last thirty years - it has tended to be related to the formation (and maintenance) of reciprocal personal relationships (and associated networks) exercised within business contexts as the basis for modern business activity (Wong and Leung, 2001). It is, however, less clear whether this form of networking - based on such a deep and abiding sense of empathy, trust and reciprocal behaviour - remains relevant and 
current in today's fast paced, somewhat volatile and changeable market situation in China, in particularly amongst younger people.

Although it can be argued that many of these terms have been applied to business behaviour in the China of the period 1978 to the recent past (that is, from the date of China's reopening to the world until now), it is less clear that they actually apply to the younger generation who are now taking over businesses. Many of these people were raised in a very different - and indeed globalised - China which is very far removed (it would seem) to the somewhat protected, tradition bound and insular China of their parents.

In one way these values could be placed in a diagrammatic context (and this has been done, in a very basic way near the end of the paper) but although they are linked in the sense that they all stem from deep traditions and collectively can help to form and maintain relationships of a guanxi nature and other aspects of cultural behaviour, the values are also distinct in their own right. For example, moderation is a very different concept in traditional Chinese thinking from balance (as Creel, 1953, notes), although they can overlap and link together at times and in certain situations and contexts. What one can suggest is that the values considered in this study form a key core range of traditional values embedded deep with the traditions of Confucian, Taoist and associates value frameworks in China. They share aspects of complexity, affectiveness (in the sense that they tend to be conceptualised at an emotional and almost intuitive level), and intrinsic value (in the sense that they tend to lie deep within Chinese culture).

\section{METHODOLOGY.}

Depth interviews were undertaken over a two year period (2007/8)with 83 Chinese residents aged between 20 and 35 living in Shanghai (6), Nanjing (5), Dalian (5), Kunming (7), Lanzhou (4), Wuhan (6), Beijing (8), Hangzhou (10), Tianjin (4), Xiamen (4), Guangzhou (5), Shenzhen (5), Suzhou (9) and Hunan (5). Each interview was conducted individually, and all respondents were interviewed for at least several hours, often over a few days, or, in some situations weeks. This cohort, as a whole, represents a generation of Chinese who have grown up with the development of a 
market economy. Each was interviewed one by one by the author. They were selected on the basis of

One of the aims of the process adopted was to avoid "leading" respondents and it was also desired to leave the interview process relatively open ended and unstructured to allow the respondents to speak for themselves, in their own way, in their own time and using a format and process best suited to themselves (some talked about each concept, others told stories, and some meshed concepts together).

The actual process, per se, used for each respondent was as follows: they were introduced to the aim and scope of the project which was to ascertain the relevance, applicability and use - to them - of a range of cultural values which have been associated with Chinese culture and traditions. Each value was introduced in the briefest of ways. The aim was not to provide a prescriptive definition of a traditional value, but to discuss them in a general (and non leading) manner, and this was usually done by referring to some studies and giving some examples - as some values (such as trust, or empathy) lend themselves to giving examples as the basis for how they are perceived in China. However, it was found that the values were well understood by respondents - this was because they are considered core values in China and are perceived to stem from Confucian, Taoist traditions which are considered to be quintessentially Chinese.

Then respondents were asked to comment on the value in almost any way they wished: to define it, to consider how relevant it was, to mull over it and, therefore, the approach was flexible and respondent driven. Care had to be taken to avoid influencing discussion in any way at this juncture, so no view was offered at all - that is, as to whether a value was relevant or not. The discussion was open ended and respondents were quite free to examine issues in their own way and time. The link between the values and business was also discussed as was the link between a value and tradition, modernity and other values. However, no actual connection was suggested in any way by the interviewer - the question was: how and if, and what do you think? In a sense, there was no view expressed. Various themes were noted and recorded (usually in a note pad format as tape / recording is not liked in China and it tends to stem the flow of discussion) and these have been synthesised in the findings 
of this paper. A range of key themes emerged and these formed the framework of the paper's discussion, and it was curious that the variations between locations were generally rather marginal.

Once initial analysis was undertaken the findings and the accompanying further analysis was discussed in further detail with each respondent as this helped to distil and crystallise some additional observations and ideas which were encapsulated into the final draft.

\section{FINDINGS.}

\section{Trust.}

Trust was still considered to be an important part of contemporary culture and associated behaviour. However, once again, it was applied rather more sparingly than in the past, and always with care and a degree of caution. Again, respondents felt that they had control over the use or otherwise of this value. It was, in a sense, valued but used sparingly. Some of the comments about this value were as follows:-

- in today's world, people tended to trust people less than in the past - they were more hesitant, and - as several people put it "gave out trust more carefully and sparingly than in the past. Today we do not just think - ok, let us trust this person - we are more cynical and sharper than in past times where people were perhaps a bit more naïve;”

- trust was now conceptualised, respondents felt, in a more complicated and structured manner than in previous generations. In the past, people might have felt almost intuitively that they could trust this or that person, but today, people tended to think about trust as a more objective, cognitive (and, to some extent, less intuitive) value. Trust could be given when a person had demonstrated sincerity, honesty, fairness, over a reasonable period of time, and not just on the basis of a blurred sense of empathy - as one person said, "It is almost as if one has to work hard to gain our sense of trust now.. and today, we think of trust as something almost measurable, tangible, complex and a value to be thought about and not just applied - or, for that matter, not 
applied. Trust is not quite a commodity but it is certainly thought about very carefully before we just trust someone.”

- similarly, trust tended to have various levels, or degrees of depth. One could trust a person to some degree, to a medium degree or far deeper: trust was now applied in a conscious manner and it was rare - very rare, respondents felt for trust to be given at the deepest level to anyone apart from very close friends and colleagues who had earned trust over a long period of time. This conscious ability to think about trust in terms of levels, or degrees of depth, underscores the tendency to view this value almost as some kid of commodity.

- to some people, trust was even discussed as being one of a number of potential values used in business as a negotiation tool - that is, an aspect of behaviour which could be applied (or not, or - to some degree) to enhance a business relationship. In some conversations, trust was removed from the world of family, friendship and culture, and conceptualised as a simple business value which could be of use, at times, and in certain contexts and situations as a weapon to enhance a business situation or position.

- trust was also divided into a range of types and categories, and in this context, respondents felt that - again, they tended to treat trust in a more concrete and specific manner than their parents. One type of trust was a deep, intuitive, and abiding sense of trust often (but not always) exhibited between the closet of friends, the best of business colleagues and family. Another type of trust was what can be termed extended trust - where one developed a degree of trust between themselves and a range of colleagues (or even family members) located within a personal or business network - for example, amongst a group of colleagues. In this situation, one or more of the network members might be considered close and very trusted colleagues, while other members of the same network might be trusted to a lower degree. However, they were all trusted, to at least some extent, as being part of a network which was both valued and useful to the person. A third category of trust was related to time where trust could be developed or deepened over time - or it could actually be extended for the life of, for example, a specific business situation or context (and, in this sense, trust trended to be conceptualised as being finite in its life span in certain situations). 
Ideally, respondents still wanted to be able to exhibit the kind of intuitive, deeply felt and complex sense of trust they felt their parents tended to use, but increasingly in today's volatile and changeable China, it was necessary to treat trust in a sparing, and carefully managed manner, to be applied only when one was certain that a colleague could indeed be trusted over a reasonable period of time. True trust was now a rare commodity. As one person noted (and the use of words, is telling): "we feel sort of bruised in today's business world, and so we want to trust but we hold back - we become somewhat cynical. Can we actually afford to trust someone when it is all about money - ideally, yes, in reality, rarely.”

\section{Balance.}

In traditional Chinese society, one often strived to achieve a sense of balance in business relations, social intercourse and life in general, but was balance still relevant in today's fast paced China? Once again, the responses received were quite opaque, in some ways - people felt that balance was still important in China, but once again, this value tended to be applied with far more overt and controlled discretion than in past years. In business negotiations and transactions, balance was also conceptualised not so much in terms of behaviour and a sense of harmony (that is, almost in a philosophical sense), but now had dimensions and connotations of balance in terms of power, money, income, status and ranking - that is, how each side in a business situation could get at least as much as the other side. Balance had now taken on dimensions of the world of modern business, and had tangible, financial and power aspects which were not particularly associated with the more Taoist sense of balance which was felt rather than observed. Today balance was a thing of business, not so much of culture and philosophy.... except, that, underneath, there was still a deeper and more philosophical view that in an ideal relationship, there still needed to be a sense of innate, intuitive and almost unmeasurable balance in which each side felt that their relationship was balanced and natural. As with so many other traditional values, underneath the current conceptualisation of the value lurked a deeper and more traditional view of the value as a part of a deeper and more hidden world in which relationships still mattered a great deal in a complex and intuitive manner and fashion.

\section{Moderation.}


In traditional Chinese society there was a sense that behaviour and the environment in which one lived and worked should exist in a climate of moderation - that there was a circumspect and encompassing path for all situations, whether they be how one lived one's life to how one conducted a negotiation. An ideal world, in traditional China, was one in which one lived one's life according to the middle way - moderate in all things and extreme in none. This value, which emanates from Taoism and associated belief systems (such as Buddhism), is one of the most traditional of values and initially respondents felt that the days of striving for a life of moderation were over. However, as this value was discussed and mulled over, it emerged that moderation was still important in the sense that - as an absolute ideal - it was still desirable to be able to achieve a sense of moderation - a middle position - in life, business and social relationships, so that there was a sense that a viable, and sensible middle position had been obtained. However, whereas in traditional times this desire for a middle position was associated with a sense of time, history and culture, today, it was (once again) conceptualised in rather more overt terms. A middle position - in business, or indeed in life - meant that one did not take undue risks, did not stand out, did not show one's negotiating hand too obviously, and demonstrated a sense of care, decorum and good business (and lifestyle) skills In short, moderation was to some extent no longer about traditional and culture, but about how to live one's life in a successful and viable manner. As with so many of the other values discussed in this paper moderation had been updated and reconfigured.

Yet once again, underneath this more contemporary view of moderation was a view that moderation was also a natural, desirable way of living - there was a sense that it was linked to values such as harmony, empathy, inclusiveness, and other values and, in short, was party of a deeper sense of being and what it was to be Chinese. Underneath if one demonstrated a sense of moderation in all things, one felt better for doing so. Once again, this value still had deeper and more intuitive overtones. It was viable in today's China in one way, but also important for a sense of internal well being.

Respondents also felt that today (and perhaps in previous times) moderation was also conceptualised in terms of the environment in which one lived and did business. For 
example what constituted moderate business or even social behaviour in Shanghai was rather different to acceptable moderate behaviour in for example Lanzhou in western China. In today's modern and dynamic china the acceptable boundaries of moderate behaviour had been significantly widened and it was now considered to be somewhat "moderate" to negotiate hard and fast and to party all night - at least in major capital cities. So, increasingly, there was a sense that moderation tended to reflect current trends, forms of behaviour and fashions in a way which was more common today than in the past. Far from being fixed in time, history and culture, it was changeable and somewhat volatile - yet underneath, there was still a more traditional and almost innate desire for moderation in all things, including business.

Once again, a respondent summed up the prevailing view about moderation:

“At a deeper level we still desire a moderate form and way of behaviour - but that is not always possible in business or in life in general. Things are so fast now, and sometimes you have to be tougher and more assertive. You can't always worry so much about tradition and so on. It sometimes is a luxury to be like this. So perhaps moderation, in its traditional sense, is now more flexible and more westernised. You have to be moderate but you also have to be western and flexible. You have to be smart that's the thing.”

\section{Face.}

Respondents felt that face was still important in their world, but again they felt that they conceptualised and used it in a slightly different manner than their parents. They noted that face was:-

- generally less important, overall, these days when dealing with foreigners, peers of their own age (to some extent, see below), and in large cities such as Shanghai where money was valued above all else - often, it was simply a situation of doing business for the sake of the business and not on the basis of relationships or matters of "saving face". So often one simply did not have time to worry too much about face... but it was still important, just not as much as in the past; 
- $\quad$ rather more important, however, if one had a high level guanxi relationship where connections and emotional bonds between people still mattered - but these were becoming somewhat rare; and

- sometimes not used at all, in situations where there was neither a guanxi connection nor indeed any but a basic and formal relationship - perhaps in a routine business context. In these situations, which were felt to be on the increase, there was a sense of "who cares", in that - as one person noted - "business is business, money is money so who cares about face and all of that - we don't care that much about the people, so we don't worry about face that much either." In these situations there was a sense that face could be applied or not applied quite ruthlessly and objectively on the basis of the type of business situation, and context.

This was a value which was therefore often conceptualised in quite overt, specific and objective terms - in the sense that often people did not care that much about face so long as their business was making money. Face could be used, or not used, in quite an assertive and cognitive manner. It was - perhaps - an adjunct to culture rather than a core and key part of culture itself. People could, as one person said, "turn face on and off depending on the situation, and often we just don't care anymore. Often we can simply treat this value in a rational and applied manner." However, if they had a deeper and more complex relationship with their business associates then face was important in a more personal and affective - and indeed - traditional manner. Face, in its most traditional Chinese sense, had not been lost or discarded, but it was now applied very sparingly and then only in true guanxi relationship situations. One does winder if face, would become more important as the respondent got older - but they felt that this would not be so, simply because they were living in an increasingly globalised and cognitive society where one had to "live in reality, and do business, and not worry too much all the time about tradition." There was a sense that face belonged to a slower, more organised and more structured society - it was perhaps part of the past and a luxury in the present. Yet there was a lingering admiration for face in some situations and contexts - that is, where one was able to form a deeper level relationship with another person or persons as the basis of a true and in a sense quite traditional guanxi relationship. Yet so often, one simply had to operate at a more 
basic and simple level - in a world of fast business and dollars and cents. As one respondent noted:

"Sure we feel hat face is important - but really, you have to also be quite smart, tough, assertive ruthless. This is - well - just a different place from a few years ago, so face is like valuable but not always relevant.”

\section{Empathy.}

In traditional China empathy exercised and exhibited between people (particularly in a guanxi situation) was a key aspect of a true guanxi relationship and respondents felt that while this was probably still so with the older generation it was far less common with their own age group. Today, one tended to be more guarded, and even cynical in behaviour than in past times. One tended to be less inclined to display a high degree of empathy to another person unless there was a deep, longstanding and multi dimensional guanxi relationship. Like trust, empathy could be applied - or not - in a quite considered, cognitive and even ruthless manner. As one person noted " we tend to be in a way both more remote and reserved with people we don't know that well (than in the past), and also, at the same time, more able to be outward and assertive so we can kind of be a bit like some foreigners - fast talking and good fun, but careful not to show our inner feelings - so we can play the game too - and empathy is therefore sometimes not applied that much unless we are very sure of who we are doing business with!. Today we "act” perhaps more than in past days - that's how it might be summed up. We pretend, but we hold back - we are fun but we are very reserved and you may not get to know us that much. So true empathy - that is a bit rare now - a desire and a dream less than a reality. In short, sometimes we will do business with you even if we don't feel that much empathy.” Once again, as in relation to some of the other traditional values tested, there was a sense of almost controlling and even manipulating behaviour in a way which - as respondents themselves noted - was less intuitive and open than in the past.

However, once a deep and abiding relationship was firmly established at a business and / or social level (usually both); a deep and powerful sense of empathy would be nurtured between the two sides as a key and valued platform of relationship 
development and maintenance. At that stage, just as with some of the other values discussed in this paper, such as trust, empathy would be applied without objective consideration - and it would be offered in an intuitive and deeply felt way. (This was because the relationship had passed into a deeper and more empathetic phase, so one could afford to relax and open up one's heart to the other person) However, this was becoming less common. In short, although a true guanxi relationship did include a deep sense of empathy exercised and nurtured between the two or more people, it was now somewhat more elusive and rare than in the past. Today one sometimes had to do without a sense of empathy and just “do business” anyway.

\section{Stability.}

If stability was a desired goal in traditional Chinese culture, it was still valued in today's China but perhaps in a different way compared to the past. Respondents still desired - overall, and as an ideal (perhaps) - a stable environment, within and outside business - and, in regard to the latter, changes in structure, partners, key personnel and so on were as disliked as ever.

However, alongside this sense of stability as a valued tradition there was also a new sense of flamboyance, innovation, creativity and being prepared to take a risk. This new sense of adventure was, respondents felt, a key aspect of their generation and was a result of three possible factors. The first was the recognition that in today's globalized market one had to change, innovate and take some degree of innovative risk frequently to remain competitive and up to date. The second reason was that thirty years ago China had been a network of state owned enterprises and people of that generation tended to prefer structure, order and systems above all - according to respondents, that is. Within the old state owned and dominated system of China from 1949 until 1978, life was all about structure, formalities, processes rigid work units, and certainly not about structural change within a state owned enterprise context (although there was plenty of social and political change - which itself might have been another reason why the respondents' parents liked stability). Respondents therefore felt that their parents had come from a system which emphasised structure, stability and order within state owned enterprises and the idea of being innovative, flexible, risk positive and change oriented was new to them. Thirdly, respondents 
believed that that they had been educated to think more as creative individuals not so afraid of standing out, making decisions, living with change and being innovative and taking risks. Today the heroes of China were change agents, people who thought and acted differently to make their fortune.

There was a link between a certain sense of the value of stability and a new found desire to be assertive and ready to undertake change, and it was this: respondents felt that the level, and range, of their new found individual and change ready behaviour was generally within a certain envelope of overall stability - put another way, they were happy to undertake change so long as it did not upset the fundamentals of society and the business itself. One could innovate and take risks - within certain boundaries. In a very real sense, respondents wanted a "bit of the old and a bit of the new" - as they often put it themselves. A leg in tradition and in the world of the new was in itself desirable and very Chinese. Change was fine so long as the ripples it caused in business, in relationships and in other contexts, were not too great!

\section{Time.}

As noted before, time in traditional Chinese culture tended to be somewhat flexible. It could speed up or slow down depending on situation, context, and relationship orientation - amongst other issues. Respondents felt that time in the China of today had three distinct meanings and "uses”, as they often noted. (Again, they felt that they conceptualised these values in a more cognitive and applied way than their parents) Firstly, the traditional sense of time as being part of a holistic whole rather than just an entity in itself was still considered to be somewhat valid and relevant (that is, time was an agent of a bigger picture - a servant of business rather than controlling a business process such as a meeting). However, and secondly, time was also now considered to be a hard and fast, quite distinctive and ruthless "entity" which could be measured. One could both consider time in a holistic and almost mystical sense and also use it in the most ruthless of ways when convenient - again, respondents used value definitions from a few worlds here.

Thirdly, time could also be manipulated - that is, one could pretend that one still viewed time as a deep, affective and holistic concept and this could be, and was, used 
as a business negotiation tool. One could speed up and slow down time orientation depending not really on the basis that one did indeed view time as a part of a larger process, but simply as an almost cynical negotiation tool ("I can make more money if I play hard to get and slow the negotiations down - or I can speed it up so that my partner, say from Australia, is struggling to deliver on time and that gives me a position of power!”). In this situation, time could be used as a weapon to win in a business situation. As with so many of the values described in this paper, time had a traditional and modern orientation and use: respondents were happy to use it in both sense and contexts. It could be both part of the whole and also a precise and useful narrowly focussed concept.

\section{Group orientation}

Group orientation remains one of the most common aspects of behaviour associated with China. As noted in the literature review, in traditional Chinese society, people tended to mix and work in groups - at home, in business and in social networks. In today's China, respondents once again had mixed and quite complex views about whether there was still a strong sense of group orientation in China. They felt that - in short, - it was completely possible and indeed viable, to live and work in the world of being a group person and also an individual - to think and work in both spheres as it were. For example, one person noted that:

"In some ways we do feel that it is still nice to be part of a group and that some groups are more important than the individual - for example, in a family situation and context and even in regard to some personal networks and groups... but we can also be very much the individual now, too, both within those groups and also in a business context - so it is possible that we can be group people and individual at one and the same time. There is probably no contradiction between these dimensions we feel...However, the old fashioned idea that one must always give into the group and never stand out, no, that is gone to some extent - but again, sometimes we want to not shine and at others we do, now we can pick and choose and move between forms of behaviour more than in the past. " 
It was this sense of being able to move in and out of types and forms of behaviour which characterised all of the respondents - of being able to pick and choose when and how to make use of traditional forms of behaviour both in a traditional and up to date manner and form. So it was with the notion of group orientation where respondents felt that they could quite happily straddle the world of the individual and the group. One could quite easily be a traditional group orientated person one minute and an individualist the next - or so it seemed to respondents. They also felt that they could also exhibit behaviour between these two poles. To the respondents it was perceived to be quite easy to move in and out of different types and forms of behaviour. They did not need to particularly think about this issue or wonder about whether they could be an individualist and also a group centred person - to them they could be both. It simply depended on the situation, the context, and the demands of the circumstance and their own view of what kind of appropriate behaviour to exhibit at that point in time.

The precise relationship between group orientation and individual behaviour was a complex one. A common sequence of statements sum up this issue:-

- $\quad$ a person could be part of a group and an individual at the same time;

- however, the level of individual and creative/innovative and individual behaviour tended to be within the overall confines of a what a group would accept at a point in time and in a particular situation and context;

- so, therefore, a person might wear some outlandish clothes, or be rather bold and assertive in a business meeting, so as to stand out - but they would tend to do this only if the group itself would accept this level of individualism; and

- therefore, some people tended to "test the water" of a group before deciding how bold and individual they could be - so this was very much a situation of individuality within the confines of what a group could accept.

Once again, the sense of adherence and use of more modern values in China is in some ways rather deceptive - it was more a situation of making use of the new in the context of the old!

\section{Guanxi relationships.}


A core of traditional (and more contemporary) Chinese behaviour was the existence of personal networks. These networks bound like minded people together for mutual benefit. The networks were usually based on deep forms of relationship in which the various people involved in the network looked after each other - developing and exercising guanxi links. Networks could be social, business, (often they covered both areas), and could be large or quite small. They could be formed amongst people of the same type and level (for example in an organisational context), or amongst people, at various levels of - for example - an organisation. Within these networks, some people could have more power than others, but some networks have been observed where most people had about the same portion of power as each other.

Whereas some values were felt to have slightly changed and perhaps lost their power and status in today's China, personal networks were felt to have, if anything, increased in power, importance, commonality and respect. What was also felt to be different was the range and types of networks used in China now. Some personal networks were formed and used for quite overt and ruthless reasons - to gain power, to obtain a promotion, to strike a deal - and there was a strong view that the world of networks had now been transferred into the world of modern business. Others however were more traditional, and were still based on deeply felt guanxi relationships. Many others were formed at varying levels of what could be termed intensity - so there were (now) formal, informal, intense, low level and basic networks rather than just a few higher level and guanxi based network as might have been expected in past years. . Today, as many said, a wide range and variety of personal networks needed to be formed and only a few - a very few - were actual guanxi networks as in the past.

Of particular importance was the observation that today many networks were formed for quite specific business reasons - and they were limited to just that - a specific business situation and context. For example, a businessperson might form a personal network with a group of like indeed business people to develop a new venture in, for example, Shanghai. The network would be sharp, specific, and clearly focussed on a particular aim and set of objectives. 
Personal networks (social, business and combined) were now also (now, perhaps more than in the past) time based and this is summed up in this table:-

\begin{tabular}{|c|c|c|c|}
\hline Length of time. & Social & Business & Combined \\
\hline $\begin{array}{l}\text { Short term } \\
\text { (under one } \\
\text { year) }\end{array}$ & $\begin{array}{l}\text { Some social networks } \\
\text { were established for a } \\
\text { short and defined time } \\
\text { period - people } \\
\text { increasingly felt free to } \\
\text { pick and choose } \\
\text { networks and friends. } \\
\text { There was less sense of } \\
\text { longevity in some } \\
\text { social network circles. }\end{array}$ & $\begin{array}{l}\text { Many networks } \\
\text { were short term for } \\
\text { a particular } \\
\text { business situation } \\
\text { and context - they } \\
\text { had no sense of } \\
\text { being over a longer } \\
\text { period of time. }\end{array}$ & $\begin{array}{l}\text { Short term } \\
\text { combined social and } \\
\text { business networks } \\
\text { were increasingly } \\
\text { common, confined, } \\
\text { sharply focussed } \\
\text { and of a particular } \\
\text { time frame. There } \\
\text { was a palpable } \\
\text { sense of being able } \\
\text { to form a network } \\
\text { and then move on. }\end{array}$ \\
\hline $\begin{array}{l}\text { Medium term } \\
\text { (one to five } \\
\text { years) }\end{array}$ & $\begin{array}{l}\text { Social networks of } \\
\text { about one to five years } \\
\text { were becoming more } \\
\text { common than in past } \\
\text { years. In a volatile and } \\
\text { changeable world it } \\
\text { was often useful to } \\
\text { expect that a social } \\
\text { network would not last } \\
\text { over, for example four } \\
\text { or five years. }\end{array}$ & $\begin{array}{l}\text { Business groups / } \\
\text { networks now } \\
\text { increasingly } \\
\text { formed around a } \\
\text { project or group of } \\
\text { projects and then } \\
\text { dissolved or } \\
\text { reconfigured after } \\
\text { about four to five } \\
\text { years: there was } \\
\text { less sense, than in } \\
\text { the past, of the } \\
\text { need for longevity } \\
\text { - in some if not all } \\
\text { situations. }\end{array}$ & $\begin{array}{l}\text { A combined social } \\
\text { and business } \\
\text { relationship/network } \\
\text { was also quite } \\
\text { common over a } \\
\text { medium period of } \\
\text { time, and could be } \\
\text { quite carefully and } \\
\text { overtly } \\
\text { conceptualised as } \\
\text { being over a } \\
\text { medium term. }\end{array}$ \\
\hline $\begin{array}{l}\text { Long term } \\
\text { (over five } \\
\text { years) }\end{array}$ & $\begin{array}{l}\text { A long term and often } \\
\text { deep social } \\
\text { relationship was now } \\
\text { increasingly reserved } \\
\text { for only very close } \\
\text { guanxi friends and } \\
\text { associates - and was } \\
\text { felt to be rare and } \\
\text { unusual rather than the } \\
\text { usual and normal way }\end{array}$ & $\begin{array}{l}\text { A long term } \\
\text { business } \\
\text { relationship was } \\
\text { also rather sparing } \\
\text { in today’s China. } \\
\text { People now tended } \\
\text { to be very wary } \\
\text { about any long } \\
\text { term commitment } \\
\text { and associated }\end{array}$ & $\begin{array}{l}\text { A long term social } \\
\text { and business } \\
\text { relationship was a } \\
\text { true guanxi network } \\
\text { relationship and } \\
\text { these were } \\
\text { becoming quite } \\
\text { rare. One had to be } \\
\text { very careful about } \\
\text { developing a long }\end{array}$ \\
\hline
\end{tabular}




\begin{tabular}{|l|l|l|l|}
\hline of doing business. & $\begin{array}{l}\text { relationships in } \\
\text { business terms. It } \\
\text { was more of a } \\
\text { dream than a } \\
\text { reality. }\end{array}$ & $\begin{array}{l}\text { term relationship } \\
\text { and associated } \\
\text { network. Today, } \\
\text { one could not } \\
\text { always be so } \\
\text { trusting and the fast } \\
\text { paced and volatile } \\
\text { world of business } \\
\text { often did not } \\
\text { particularly allow } \\
\text { for a long term } \\
\text { view. }\end{array}$ \\
\hline
\end{tabular}

Respondents felt that whereas in the past networks were based on a more empathetic sense of people relating to each other for mutual benefit, now there was also a sense that networks could be finite in terms of time, role and function. They could be formed, developed and even disbanded in a more rational, empathetic and assertive manner than in the past. There was a far more analytical view - they felt - about the whole role of guanxi networks than in the past.

Another way networks were often discussed were in regard to type of network (and relationship) associated with the depth and level of commitment given by the people involved. Once again, the data came from respondents, who treated guanxi networks in the most cognitive and assertive of manner: -

\begin{tabular}{|c|c|c|c|}
\hline $\begin{array}{l}\text { Level of } \\
\text { commitment }\end{array}$ & Social & Business & Combined \\
\hline $\begin{array}{l}\text { Low level of } \\
\text { personal } \\
\text { commitment. }\end{array}$ & $\begin{array}{l}\text { It was now quite } \\
\text { common for people to } \\
\text { have networks and } \\
\text { associated relationships } \\
\text { operationalised at a } \\
\text { quite superficial level - } \\
\text { and some respondents } \\
\text { felt that this was } \\
\text { something of a break } \\
\text { with the past. Of } \\
\text { course, it had always } \\
\text { been the case for some } \\
\text { people to have low } \\
\text { level social networks, } \\
\text { but today this was both } \\
\text { more common and } \\
\text { more deliberately } \\
\text { planned and executed, }\end{array}$ & $\begin{array}{l}\text { Business networks } \\
\text { which exhibited } \\
\text { low levels of } \\
\text { commitment were } \\
\text { also increasingly } \\
\text { common and again } \\
\text { this was felt to be a } \\
\text { slight but } \\
\text { pronounced break } \\
\text { with the past. } \\
\text { Today, people } \\
\text { wanted to treat } \\
\text { "business as } \\
\text { business” and } \\
\text { sometimes did not } \\
\text { want to give too } \\
\text { much to the } \\
\text { associated }\end{array}$ & $\begin{array}{l}\text { Similarly, low } \\
\text { level and basic } \\
\text { associated } \\
\text { networks were also } \\
\text { on the increase as } \\
\text { people adopted an } \\
\text { increasingly } \\
\text { pragmatic approach } \\
\text { to business and } \\
\text { social lifer, at least } \\
\text { in a wide range of } \\
\text { situations if not in } \\
\text { all con texts. } \\
\text { Today, they } \\
\text { reasoned, we are } \\
\text { busy and we just } \\
\text { don’t have the time } \\
\text { to worry about }\end{array}$ \\
\hline
\end{tabular}




\begin{tabular}{|c|c|c|c|}
\hline & $\begin{array}{l}\text { as a deliberate and } \\
\text { often forthright } \\
\text { strategic position. }\end{array}$ & $\begin{array}{l}\text { networks and } \\
\text { relationships. This } \\
\text { was particularly so } \\
\text { in the case of larger } \\
\text { cities such as } \\
\text { Shanghai and } \\
\text { Beijing. "Just treat } \\
\text { people as business } \\
\text { partners" was a } \\
\text { common phrase. }\end{array}$ & $\begin{array}{l}\text { deeper relationship } \\
\text { issues. }\end{array}$ \\
\hline $\begin{array}{l}\text { Medium level } \\
\text { of personal } \\
\text { commitment. }\end{array}$ & $\begin{array}{l}\text { There was also a sense } \\
\text { that social networks } \\
\text { operationalised at a } \\
\text { medium level of } \\
\text { commitment were } \\
\text { common now. People } \\
\text { would think that they } \\
\text { would give the network } \\
\text { a certain level of } \\
\text { commitment - a certain } \\
\text { push if one can us this } \\
\text { phrase - but in a } \\
\text { carefully thought } \\
\text { through and planed } \\
\text { manner. These } \\
\text { networks were } \\
\text { important they were } \\
\text { taken seriously, but one } \\
\text { did not reveal anything } \\
\text { like one’s all in such a } \\
\text { network. }\end{array}$ & $\begin{array}{l}\text { These types of } \\
\text { medium level } \\
\text { business networks } \\
\text { were also common } \\
\text { and on the increase } \\
\text { for significant } \\
\text { projects which } \\
\text { often had a medium } \\
\text { term time scale and } \\
\text { orientation. One } \\
\text { could carefully } \\
\text { plan such a } \\
\text { network and could } \\
\text { maintain it at a } \\
\text { medium level - } \\
\text { serious, committed } \\
\text { but not one which } \\
\text { would operate at } \\
\text { the very deepest } \\
\text { level. }\end{array}$ & $\begin{array}{l}\text { Combined medium } \\
\text { level networks } \\
\text { were also common } \\
\text { and on the rise. } \\
\text { People felt that } \\
\text { once again it was } \\
\text { possible and often } \\
\text { viable to form and } \\
\text { maintain a network } \\
\text { which was } \\
\text { operationalised at a } \\
\text { medium level of } \\
\text { commitment - to be } \\
\text { taken seriously but } \\
\text { not to take up too } \\
\text { much time and } \\
\text { emotional } \\
\text { commitment. }\end{array}$ \\
\hline $\begin{array}{l}\text { High level of } \\
\text { personal } \\
\text { commitment. }\end{array}$ & $\begin{array}{l}\text { These relationships and } \\
\text { associated networks } \\
\text { were not like "rare } \\
\text { jewels" as some said, } \\
\text { and were valued above } \\
\text { all relationships and } \\
\text { networks. They were } \\
\text { considered of vital } \\
\text { importance and value } \\
\text { but were increasingly } \\
\text { rare and were often } \\
\text { developed with close } \\
\text { friends and colleagues } \\
\text { who had stood the test } \\
\text { of time. In a pragmatic } \\
\text { world of change and } \\
\text { flexibility, such } \\
\text { demanding } \\
\text { relationships were }\end{array}$ & $\begin{array}{l}\text { Business } \\
\text { relationships at this } \\
\text { level were also } \\
\text { quite rare and were } \\
\text { maintained with } \\
\text { very old friends, } \\
\text { colleagues and } \\
\text { associates. Today it } \\
\text { was often very hard } \\
\text { for one to form and } \\
\text { maintain } \\
\text { relationships and } \\
\text { networks with a } \\
\text { high and intense } \\
\text { degree of } \\
\text { commitment. Yet } \\
\text { - as with high } \\
\text { commitment } \\
\text { personal networks }\end{array}$ & $\begin{array}{l}\text { Again, as with high } \\
\text { commitment social } \\
\text { and business } \\
\text { networks, these } \\
\text { combined networks } \\
\text { were becoming rare } \\
\text { yet admired; sought } \\
\text { after yet } \\
\text { increasingly elusive } \\
\text { in the society of } \\
\text { modern China } \\
\text { which was often } \\
\text { more concerned } \\
\text { with short term } \\
\text { goals, aims, } \\
\text { aspirations and } \\
\text { realities. Such high } \\
\text { commitment } \\
\text { networks were }\end{array}$ \\
\hline
\end{tabular}




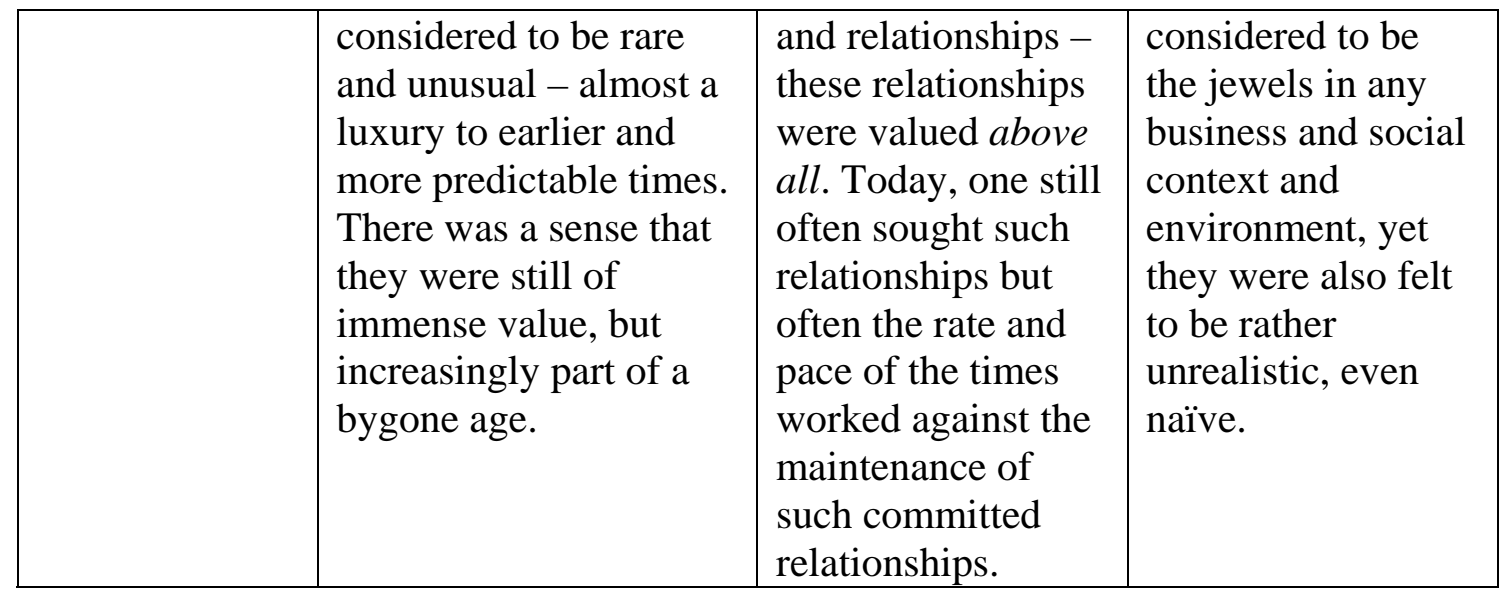

There was some nexus between the level of commitment and the length of time of a network and relationship(s), but this was not always the case. However, it was usual for high levels of commitment to be given to longer term relationships and networks it was just that this did not often happen because of the fast pace of change in China. What did happen was that relationships and networks tended to shift, change, re-form and redevelop faster than in the past - today, one might have a group of friends in one network, reform this into a new network, and so on depending on the job, the situation, the issue at hand, and the demands of the moment. Many people felt that most relationships and associated networks of people tended to shift almost constantly now and far more than in the past - in this sense, they argued, these networks were now more like what one might find in a western country - they were pragmatic, realistic, often less demanding, often less committed and often les draining.

This whole view of the types, forms and associated aspects of networks was felt to be a break with the past. No longer were networks formed on an emotional and affective plane.. They were now conceptualised, rationalised, evaluated and organised according to a range of aims, objectives and even timeframes. This whole view tended to reflect (to respondents) a far more westernised view about personal networks what they were, how they could be used and how they could be operationalised.

Yet underneath these new style pragmatic and often overtly manipulated networks remained a deeper level - and view - of networks and these were both more valued and far older (and more Chinese) in their orientation. These networks remained deep, committed, long term and highly valued and it was at tis deeper level where often major life decisions were made. These networks were formed with old friends some key family members, friends from college - and they were considered as rare and 
increasingly isolated jewels in what was otherwise a world of change and fast paced decision making. Whereas the aforementioned networks were often observable to others, clear in intent, and formed with a sense of purpose (to build a shop, to manage a business, to go to college together etc), these deeper networks were less visible, less clear in intent and more important in terms of moulding the views, aspirations and lifestyle of the participants. They were often very powerful, and yet extremely elusive - and they were still there in today's China, but were now increasingly rare and - sought after. The issue and importance of these two clear tiers of relationships and associated networks will be considered later in this paper as they had a range of ramifications for business people.

\section{FURTHER DISCUSSION AND ANALYSIS.}

All of the values discussed tended to be conceptualised by respondents in both a traditional and modern way. The traditional view of a particular value, such as trust, was deeper, more intuitive, less precise, more complex and less rigid than when the same value was discussed in a more modern orientation where it was conceptualised in more specific, cognitive, measurable, business to business and discrete terms. Whereas a traditional view of a value might be discussed in terms of its historical, cultural and, indeed human, dimension, a more contemporary discussion of the same value would treat it as a specific and almost measurable aspect of behaviour.

The way in which these two conceptualisations, of the same value, linked to each other, was various and a variety of processes can be identified based on respondent's own observations.

In some cases there was a hierarchical relationship between the two ways of thinking and talking about a particular value. This was the most common view and was expressed by over $80 \%$ of respondents. This was how they saw the issue in a basic way. In this situation the modern conceptualisation of the value tended to sit at the top of the older and more hidden view:-

Modern view of a value (specific, discrete, measurable) 


\section{Traditional view of the value (less specific, more holistic, less tangible)}

This perception was held where the modern view of a value tended to dominate their world. The traditional conceptualisation of a value was still there but it was deeper and less visible.

At times, however, there was a more integrated view of these values:-

\begin{tabular}{|l|l|}
\hline Traditional & Modern \\
& \\
\hline
\end{tabular}

In this scenario, the respondents tended to blur the line between the two views of a value, feeling that the two sides of a value - modern and traditional were often linked together. There was no clear and precise line between where one stopped and the other started. One was in a sense the outcome of the other and one was the mirror of the other, as well. In this sense, the views of the value tended to merge and blur. There was a sense of some degree of integration rather than separation.

Another view was that the values were linked together in a kind of oscillating pattern as follows:-

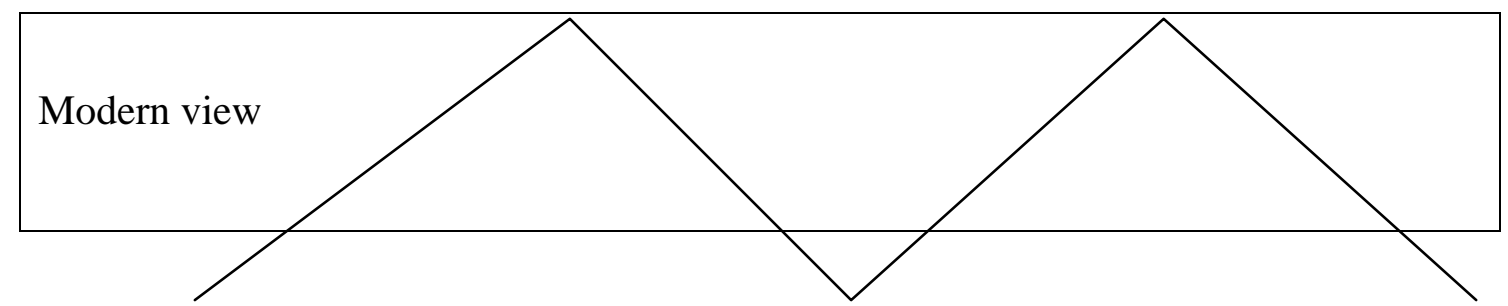


Traditional view

In this conceptualisation, people tended to move between their views of a particular value in a back and forth manner (represented by the angled lines) over time and when the need arose - often depending on the situation and context at a particular point in time. All respondents felt that this was how they dealt with values over time and in particular situations and contexts. They often felt happy moving between these two worlds, as it were, and did not feel that one view of a value was in any way contradictory to the other - they simply drifted from one to the other over time. They lived and worked happily in worlds, a cognitive, tangible one, and a less specific, and more affective and indeed historic al one. Their movement between one world and the other could be over any period of time - from a few minutes to a few weeks - theirs was a flexible and ever changing world, and this was a very common view amongst most respondents.

On the other hand, some respondents felt that there was another way of viewing these values and this was a process of what some termed dislocation - where the respective views of the values actually drifted apart over time:-

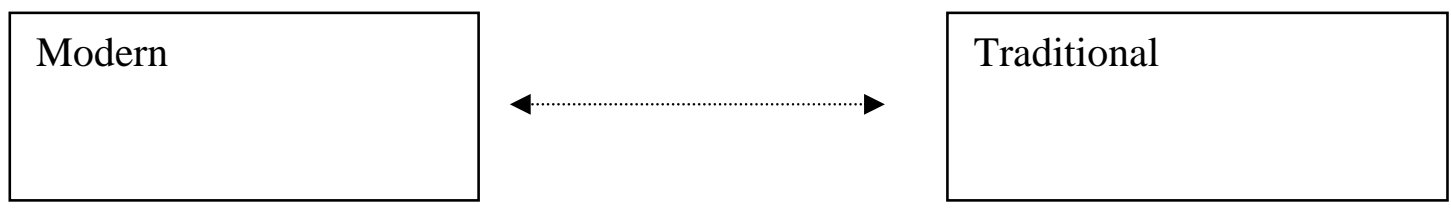

In this situation, or scenario, the two views of a value had drifted apart and people lived in one or the other but rarely the two. They were either "modern people" or, a good deal less commonly, "traditionalists". They felt that there was a vast gap between these two views of the world and of specific values, and they preferred to only live and work in one. This attitude was observed in a few examples and locations, such as Shanghai, where people fel that they had - at least to some extent, and in certain situations - done away with the old view of values. Lurking underneath their modern world however, was still some degree of traditionalism, but it was well 
hidden, and often very distinctly separated - perhaps only visible to close friends and long term colleagues.

Reconfiguration was a termed used by some other respondents, and in this situation, the view about values - in terms of traditional or modern conceptualisations - would change over time. At one time one might think and feel about value in a traditional manner but at others they would think more assertively and ruthlessly about how to make a value - such as guanxi relationship - work for them. Reconfiguring how one thought and felt about a value was common in China. Respondents tended to feel that values drifted and were often reconfigured over time according to particular situations, contexts and circumstances. They wished to make the point - in almost every interview - that values - in their traditional and modern modes - tended to live a complex and often variable life within their own minds. Here were - almost - blocks of values - western, traditional - intersecting, clashing and at time integrating with each other.

Similarly, some respondents used the term replication in their discussion of particular values. They felt that at times they would replicate - or perhaps transfer would be an equally appropriate term - how they felt about one value to other specific values - that is, if they were feeling particularly "international" they would sometimes apply this view of the world to all similar values. This sense of transferability, where one could think and "feel", about a range of values in a simular manner, was often raised by respondents who felt that this type of behaviour was quite valid in today's world with its mixed messages international orientation and sense of change.

In a sense, all of these views about how traditional and modern conceptualisations of values related to each other were related and -part of a bigger picture. This picture could look something like the following:-

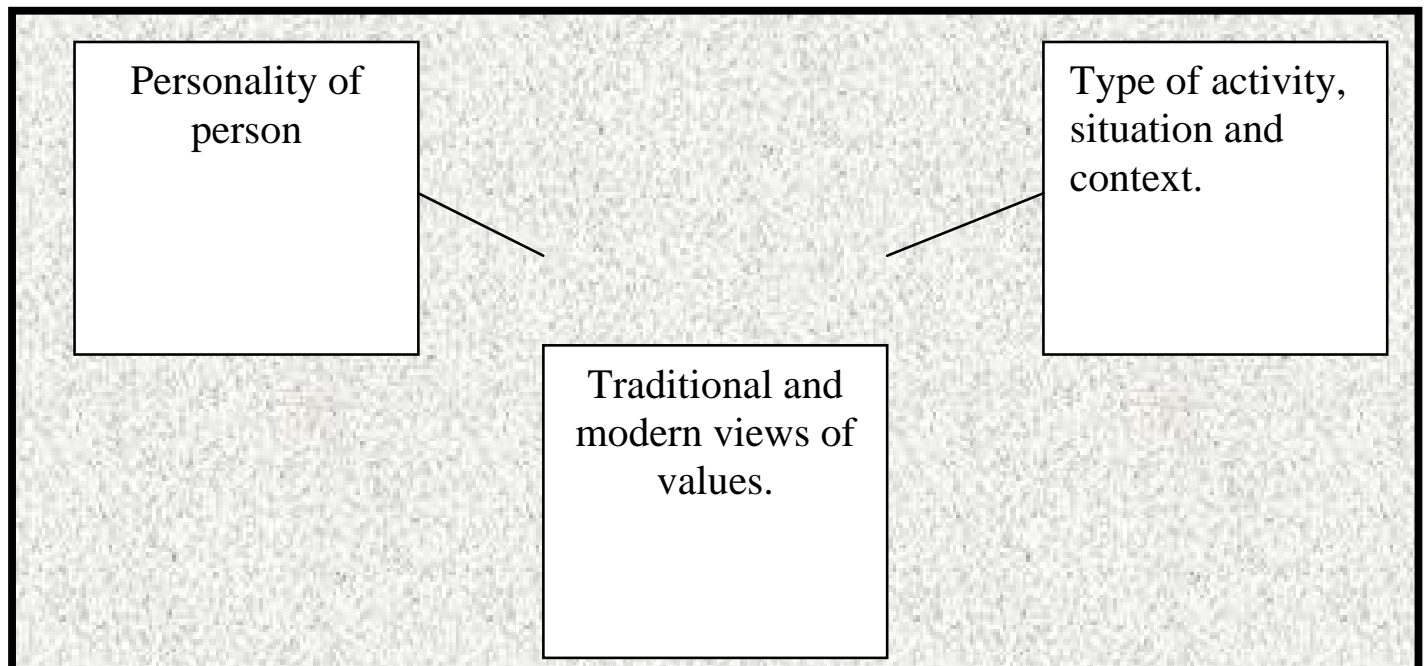



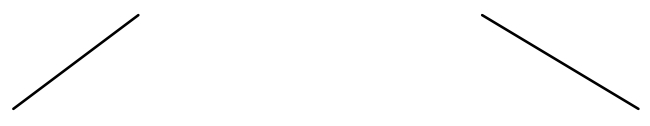

\begin{tabular}{l|l|l|l|} 
In this & View of friends \\
traditio & hecation of \\
person
\end{tabular} the nature, or personality, of the person. If they had a leaning towards modern (or, for that matter, traditional), behaviour, they would tend to lean towards that particular orientation overall. Similarly, if there friends had a particular set of views, this could also affect their orientation - perhaps they would drift away from their initial view toward that of their friends. Both of these factors - oneself and one's friends had a strong personal aspect to them, and were about the individual and how the individual interacted with close friends.

However, the location of a person - that is, their physical environment, could also impact on their traditional/international behaviour. If they were in a modern shopping centre, there was a tendency to view values in a more modern, western, discreet and measurable manner. If people were located in a more traditional part of town, they might tend to be a little less specific and modern in their views. This was not, of course, a hard and fast rule, but there was a link between environment and behaviour indeed there was between activity and perception of values. If one undertook a certain type of behaviour - for example, going to a western shop compared to eating in a traditional chines restaurant wit family, this activity, and its context - could also impact upon behaviour and the way in which values were conceptualised.

At times there would be a degree of confluence between the various factors influencing attitude and perceptions. At others, and this was by no means uncommon, there was a degree of conflict between these factors. For example, one might hold 
certain views about behaviour and these might be at loggerheads with one's friends, in a certain context, and while undertaking a certain activity - and, this would tend to cause a degree of confusion within the affected person - perhaps they might feel in a traditional frame of mind about a value, while everyone else was acting in the opposite manner. In this situation, the person might capitulate to the group's side, or drift, in a somewhat jagged manner, between traditional and modern orientation and associated behaviour. There could even be a sense of tension and discomfort in the room, as if no one was quite sure what to believe in and how to behave. At times, there could even be a sense of isolation, whereby the person would withdraw from the group, and the surrounding environment, choosing to keep their own company and viewpoint in a situation where they felt they were under pressure from others. This could be the case where a range of factors coalesced to make a situation, or context, which was unappealing to the person involved. There were also situations of some dislocation where some factors did not seem consistent with the others. For example, some times, the location and activity might be in some degree of synthesis or harmony (for example shopping in a modern international part of Beijing), whereas the personality and the group orientation of friends might be feeling in a different way - for example perhaps they would all feel that they would rather escape to a quiet and more sedate (and traditional) part of town. In this example, the nature of the individual and his or her friends would tend to dominate over environment and activity but the opposite could also be the case.

Another way in which the various influencing factors related to each other was in a kind of swirling motion, where one would impact on the other which would impact on the third, and so on. For example, the view of friends would influence the personality and associated behaviour of the individual, and these would impact on the perception about location and activity. This fluid relationship had at least three outcomes: a situation of neutrality (where the opinion of the person would not change one way or another - that is, they would remain wedded to their pre-existing view about a value or range of values), the development of a more western/modern orientation towards the value, and, thirdly, the establishment of a more traditional view of the value. The speed of this motion driven process could also vary - from fast to slow so that the rate of perceptual change could also be affected - one could move quickly from one view to the other (and in between), or much slower. The motion could also be "up and 
down”, as it were - that is it was possible for a person to change his or her view depending on the interaction of these factors so that they would change their min $d$ quite quickly, and then change it back again. It was often, if not always a volatile and changeable climate and situation and this tended to have some impacts on business negotiations where the person could change their persona from modern to traditional quite quickly. Any or all of the factors could also be the trigger for a motion driven change - it could be something about the personality, the location, activity or indeed the view of friends and there was not a view that one set of factors outweighed the others in terms of importance and power to effect change.

The aim of the above section is really just to make the point that values were considered in a variety of ways by respondents and they tended to move around, drift and reconfigure depending on a range of circumstances including circumstance, context, situation and so on. Yet there was also a sense that the traditional dimension of values was under real pressure, and that they had to be constantly conceptualised and often applied within the framework of modern pressures, trends and influences from at home and abroad. However, there was also a distinct sense that the core values of thee concepts had changed, perhaps forever - even at their most traditional, these values now had a sharper, more assertive and more ruthlessly applied aspect to them. It was as if they were - at least - at times - migrating to a new and more western / international world.

\section{APPLICATION OF FINDINGS.}

In a business context the findings have some specific relevance. Today's Chinese business people, according to respondents, would tend to apply the more modern applications of traditional values to their meetings, negotiations and subsequent business activities including relationships. To this end, they would be quite direct, ruthless, specific, overt, assertive, and "upfront”. It was not that they did not value concepts such as empathy and face - it was just that they tended to conceptualise and use them in different ways.

However, underneath this new level of directness and accompanying assertiveness, (which could unnerve unwary foreign negotiators, armed with a handbook on 
traditional Chinese values) lay a deeper strain of behaviour and these deeper sentiments (more reflective, emotional, affective and personal) would also be important in cementing and maintaining a business relationship. As one respondent said:-

"It is a bit strange but even as we almost act the part of the dynamic, modern, assertive business person, we still - underneath - and often very underneath! - still look (often these days in vain), for something deeper - far deeper - a more traditional and emotionally driven sense of trust, respect and guanxi - but we realise that in today's fast paced living (environment), it is often not possible to achieve this deeper level of relationship formation in a business climate - but to us, underneath it all, this is still the ultimate."

In short, often there were two levels of behaviour operating within a Chinese person doing business. Often business would be driven and managed at an international and very overt level, where values were conceptualised and applied in quite a ruthless and direct manner, just as one might see in New York or London. Doing business at this overt, direct and somewhat superficial level was fine for short term, basic and easy business situations and transactions, but it was not enough for a longer term, larger and more complex business situation, such as a long term joint venture. In this situation, respondents still desired the application and use of some more traditional views of Chinese values - so that, for example, they would need to "feel" that concepts such as trust empathy and respect were being applied at a deeper and more emotional level - people still strove for a true guanxi relationship even those these were increasingly rare.

This tendency to operate at two distinctly different levels could be somewhat disconcerting. Business people probably need to be ready to deal with Chinese negotiators who might exhibit two distinctive different forms of behaviour about often the same sorts of values. These can be summed up as follows:-

Level one - associated with the modern Chinese business person:-

- $\quad$ assertive, direct, forceful

- project driven 
- results driven

- business for the sake of business (limited personal involvement at a deeper social level)

- business as a one off situation (ie, we collaborate for mutual benefit but this once, with no guarantees of future collaboration)

- concerned with tangibility and measurability of a business collaboration (can I measure, monitor and document this business activity)

- Business as an overt and non emotional transaction.

Level two: - associated with deeper and more traditional cultural values and their application in a business context: -

- emotional, affective, intuitive, concerned about issues of depth, commitment and perceived innate value at a variety of levels

- person driven (at a deep and emotional level) - that is, I trust the person, so let us drive this project

- holistically driven - in which the results and the tangible aspects of the project were part of a larger whole - the project is part of a wider and deeper emotional environment.

- business for the sake of relationships - in which the business was part of a deeper and more long term relationship environment and context

- business as part of a long term process to develop and build emotional trust and a range of business and social situations and contexts

- concerned with intangibility, emotional feeling, perception, attitude, depth of trust and guanxi - a deep, rich feeling of innate and long term trust and mutual value at a deep and emotional level

- business as a deep, almost mystical outcome of a relationship driven environment and world view.

If a person wanted to establish and undertake a basic, short term and overt form of business such as a simple buyer - seller situation, then the use and application of level one values would be just fine but if they wanted to develop a deeper and more complex and often longer term business situation, they needed to be ready to at least try to negotiate and manoeuvre in level two values. As several people noted, the true 
road to long term and lucrative business success came from being able to move from basic, level one application of values to a deeper level of relationship development as this was where true and long term business still tended to be undertaken in many situations. This was the traditional heart and core of behaviour and it was still there at least for long term business alliances. If one only lived and worked in a level one world, as it were, one was very much an outsider, not really doing business at a deeper level. One would be denied the larger contracts, the bigger business deals and the insider's view of the Chinese business world. Given that such relationships were felt to be increasingly rare, it is even possible to suggest that in some ways "doing business in China" was now rather more complicated than ten years ago. After all, in today's China, one had to negotiate at a variety of cultural levels and live and work in a perplexing range of worlds.

\section{LINKAGE BETWEEN THE CONCEPTS?}

Each of the values discussed so far seems to be linked in some ways. After all, a sense of balance can help to create a sense of trust and the values collectively helped to form a guanxi relationship - in a traditional sense, that is.

This linkage can be depicted in the following diagram which also seeks to make an additional point: that each value (in a traditional, or, certainly, a more up to date conceptualisation) also stood on its own and did not in every situation, and as a matter of automatic behaviour, link to the other. Sometimes, values came together, but at other times they did not at all.

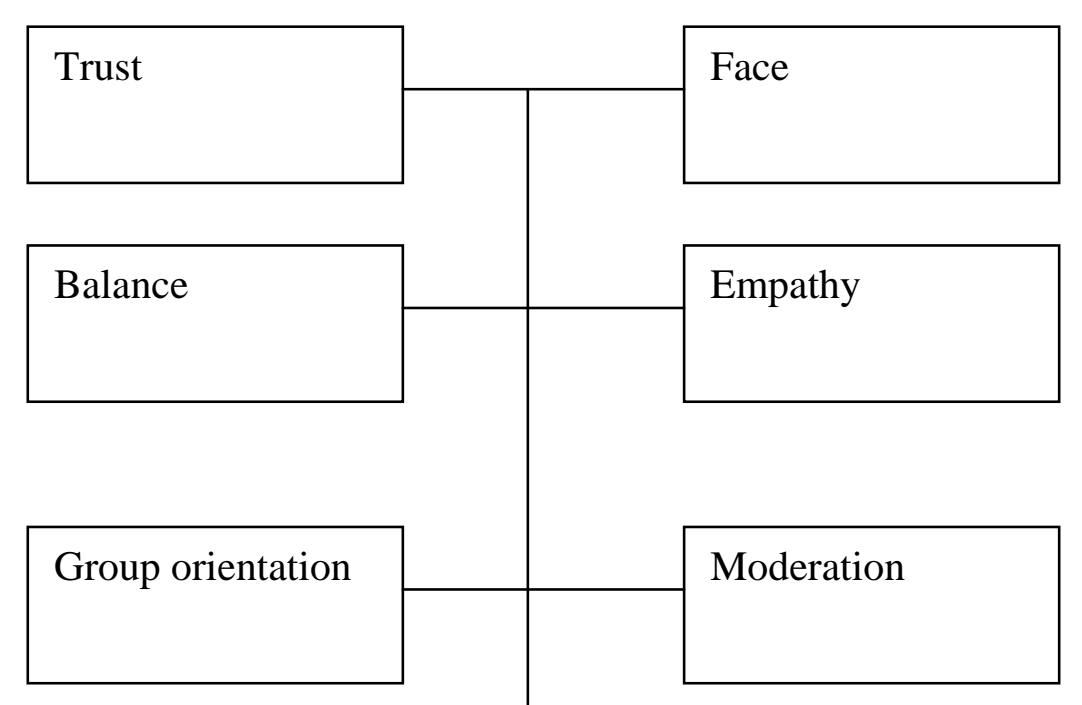




\begin{tabular}{|l|l|}
\hline Time & Stability \\
\cline { 2 - 3 } & \\
\hline
\end{tabular}

\section{Guanxi}

To be sure, at times each value added to the other, intersecting and interacting to create a sense of harmony and cultural synergy, but at other times and in other situations and contexts, each value was separate (hence no arrows on the lines in the diagram). Just exercising a sound sense of face and trust did not per se create a guanxi relationship, but they certainly helped. However, a guanxi relationship did depend on the other values being at least understood and exercised to some salient degree. Nevertheless, each value stood, also, in its own way and its own world. Increasingly, the definition and nature (and indeed, focus) of these values had - as noted, hardened, and become more assertive and sharp edged.

\section{CONCLUSION.}

Traditional values were still very much alive and well in China but they were often hidden and masked by more assertive and modern styles of behaviour and conceptualisations of traditional values such as empathy, trust, moderation and balance. It was not that the old views of these values had gone, it was more that they had been augmented by a more specific, tangible, assertive, and less deep and affective view of what they meant. Whereas at one time (and in the fairly recent past, according to most respondents), these values had been steeped in traditional heritage, and a certain sense of holistic vagueness (rather like a traditional Chinese painting where each part tends to merge with the others so that no one part stands out although all have equal value), today's conceptualisation of some of the more traditional values and how they were viewed had become sharper, more discursive, and far more emphatic and measurable. Yet underneath respondents still believed that the older, 
less specific and more mystical aspects of these values still held considerable drawing power for them, particularly in regard to the formation of a deep and long term guanxi relationship.

For the foreign (and indeed, Chinese) business person of today, "doing business" in the China of the twenty first century may be even more perplexing than in the past. Today, one does not just negotiate at the traditional and intuitive level but also at the international modern level. One's Chinese hosts might be quite traditional at one moment, and quite New York at the next! But underneath it all, there is still a sense that for long term and genuinely sound business to occur, one must still enter the China of the past, albeit through westernised edifices. Success at the deepest level will come to those who can break through the international artifice of the modern Chinese negotiators and get to their heart where values of trust, respect, empathy and Guanxi still reside at their most pure. But this world is becoming particularly elusive and hard to find: almost a dream, of the past, a vision of very different days when trust was all and empathy the basis for pure long term guanxi relationships.

Alon, I., and Mclntyre, J., (2005), Business and Management Education in China, Hackensack, NJ World Scientific publications.

Barme, Geremie., (1999), In the Red: On Contemporary Chinese Culture, Colombia University Press

Bond, M, (1992), Beyond the Chinese Face: Insights from Psychology. Hong Kong, Oxford University Press.

Bourdieu, P. (1977), Outline of a Theory of Practice. Cambridge University Press, Cambridge.

Canyon, A. (Ed), (1997). Assessment of China into the 21st Century.New York: Nova Science Publishers.

Child, J., (1994), Management in China During the age of reform, Cambridge University Press, England. 
Creel, H., (1953), Chinese thought from Confucius to Mao Tse-tung, University of Chicago Press, Chicago.

Eberhard, W. (1971), Moral and Social Values of the Chinese Collected Essays, Chinese Materials and Research Aids Services Center, Occasional Series, No. 6 (No other details available).

Fang, Tony and Ghauri, Perez (2001), Negotiating with the Chinese: A Socio Cultural Analysis. Journal of World Business, 36 (3), $303-325$.

Hofstede, G., (2001), Culture's Consequences: Comparing Values, Behaviours, Institutions and Organizations Across Nations. Sage Publications, California.

Hoon - Halbauer, S. K. (1999), Managing Relationships Within Sino Foreign Joint Ventures. Journal of World Business 34(4): 344-371.

Huang, Heh Jason, Dastmalchian, Ali, (2006), Implications of Trust and Distrust for Organizations: Role of Customer Orientation in a Four-Nation Study. Personnel Review, V. 35 (4), 361-377

Hung, Flora, (2004), Cultural Influence on Relationship Cultivation strategies: Multinational companies in China. Journal of Communication Management; V. 8 (3), 264-281

Hutchings, Kate, (2002), Improving Selection Processes but Providing Marginal Support: A Review of Cross-Cultural Difficulties for Expatriates in Australian Organisations in China. Cross Cultural Management: An International Journal, V 9, (2), 32-57.

Johnston, B. (1996). Boxing with Shadows, Travels in China. Melbourne: Melbourne University Press.

Laaksonen, O. (1988), Management in China During and After Mao in Enterprises, Government and Party, Walter de Gruyter Berlin, Boston and New York 
Lee, Tat (2005), Development of Management Philosophy for Chinese Business Environment

Management Decision, V. 43 (4), 542-550.

Li, A., Murphy M., \& Weiner, R. (1997). Living in China, A Guide to Teaching and Studying in China Including Taiwan. San Francisco: China Books and Periodicals, Inc.

Lin, Xiaohua, Miller, Stephen, (2003), Negotiation Approaches: Direct and Indirect Effect of National Culture, International Marketing Review, V 20, (3), 286-303

Ma, Zhenzhong, (2006), Negotiating into China: the Impact of Individual Perception on Chinese Negotiation Styles, International Journal of Emerging Markets, V. 1(1), 64-83.

MacInnes, G. (1993), "Guanxi or Contract: A Way to Understand and Predict Conflict Between Chinese and Western Senior Managers in China Based Joint Ventures," in D McCarty and S Hilde (Eds), Research on Multidimensional Business Management and Internationalisation of Chinese Enterprises (pp 345-351), Nanjing: Nanjing University.

March, R. (1997), Managing Business Relationships with East Asia: Building and Pilot Testing a Model of Long Term Asian/Western Business Relationships, University of Western Sydney, Sydney.

Mee, K., N. (1993), "Managing International Joint Ventures", in Lane Kelly and O. Shenker (eds), International Business in China .New York; Routledge.

Morgan, R., and Hunt, S., (1994), The Commitment-Trust Theory of Relationship Marketing in Journal of Marketing, 58 (July), 20-38).

Osland, Gregory, E., (1990), Doing Business in China: A Framework for Crosscultural Understanding, Marketing Intelligence and Planning, V. 8 (4).

Panagariya, A. (1997). Unveiling the Mysteries - Foreign Trade Regime: A View from Jiangsu Province, World Bank Research Working Paper, Washington D.C. 
Pang, Chee Keen, Roberts, D., and Sutton, John, (1998), Doing Business in China: the Art of War? International Journal of Contemporary Hospitality Management; V.10 (7).

Punnett, B., and Yu, P., (1991), Attitudes toward Doing Business with the PRC. In Shenkar, O., (Ed), Organisation and Management in China, 1979-1990. M.E. Sharpe, Inc. Armonk, New York.

Rondinello, D and Roehrig, M., (1994), Foreign Joint Ventures in Contemporary China, Basingstoke, McMillan

Shenkar, Oded (1991). Organisation and Management in China, 1979-1990, Armonk New York, London, M.E. Sharpe.

Tang, X. (1994). Innovations in Teaching and Learning in China Since 1980:

Retrospects and Prospects, paper presented to Fourth International Conference on Chinese Education in the $21^{\text {st }}$ Century, Shanghai

Tu, W.M., 1995. Selfhood and Otherness in Confucian Thought. In: Marsella, A.J., DeVos, G., and Hsu., LK., Culture and Self: Asian and Western Perspectives. New York: Tavistock.

Wee, C.H., (1994), "Research on Chinese Management, Some Issues and Challenges." In O.Yau (Ed.), Proceedings of Symposium: Theorising about Chinese Business and Management, Hong Kong Polytechnic University, Hong Kong.

Wong, Y.H., and Leung, T. (2001), Guanxi: Relationship Marketing in a Chinese Context, Haworth Press, New York.

Xu, B.Y. (199l), Marketing to China: One Billion New Customers, NTC Business Books, Illinois, USA.

Willis, M. (2004). "The Application of the Chinese sense of "balance" to Agreements and Alliances Undertaken between Chinese and Foreign Institutions in the Chinese Higher Education Sector: Adding Depth to a Popular Cultural Concept. Journal of Marketing for Higher Education. 
Wong, Yim Yu., Thomas Maher, (1998), Doing Business with Dragons of Different Breeds: Some Important Differences between China and Japan. Management Research News, V. 21 (4/5), 45-54.

Xiansheng, D (1998), Ownership, Control and Performance of International Joint Ventures: the Case of the People's Republic of China, PhD thesis, University of Illinois at Urbana-Champaign.

Yang, Jiaqin, and Lee, Huej., (2002), Identifying key factors for successful joint venture in China. Industrial Management \& Data Systems. V.102 (2), 98-109.

Ying, Fan, (2000), A Classification of Chinese Culture, Cross Cultural Management: An International Journal, V.7 (2), 3-10. 
Perhaps more than any other country in the world, China exemplifies the dichotomy between tradition and modernisation, localism and internationalism. As this massive country modernises and interacts with the global business community, a new generation of managers has emerged. This is the generation which has been born into a China open to the world, and their value systems have arguably come from Asia, Europe, America, - and home. They are the first global business citizens of China. This study aimed to identify how a range of traditional Chinese values have fared amongst the younger generation (aged between 20 and 35), and it found that these values have often been changed, reconfigured and in a sense hardened to reflect the business realities of the new China.

At the same time, however, respondents still made use of traditional values in a more pure and affective form as the basis for longer term and deeper guanxi relationships which was still where more serious business activities took place. In a sense, then, they lived and worked at two levels: what they felt to be a western level, where one forged business relations on the basis of the here and now (using concepts such as trust and face in a somewhat sharpened and abbreviated manner), and at a far deeper and more traditional level, where deep traditions and associated conceptualisations of values such as face and trust still helped them to forge and maintain more serious personal, social and business relationships. The challenge for businesspeople is to get to know and understand the new Chinese business leader who in a very real sense is now at home in both east and west - traditional and modern worlds.

What this means for managers form the west is a more complex China than hitherto they now stand a very god chance of dealing with Chinese business people who can live, work and think in two worlds - their own traditional Chinese world and also, a western world of more concrete values and forms and modes of behaviour. The person a western manager might face in Shanghai, for example, might be able to live and work in a variety of contexts and situations - so the old view of Chinese as being almost uni-dimensional (and echt Chinese in their core value systems) - if this every correct, is now no longer so. If the Chinese negotiator of today can live and work in multiple worlds, so too must a foreign business manager - they need to understand that the real heart, soul and core of Chinese behaviour (encompassing business behaviour) still lies in tradition, but they also need to be able to negotiate with a Chinese colleague who might be as sharp, hard, ruthless and project focussed as they are. Such is the shifting sands and climate of China, its culture and its people. Finally, they also need to recognise that traditional values have in their own way adopted a more sharply etched and more overtly focussed image and persona. "Face" in China is still "face" but now it may be measured, given a value, and compartmentalised in a way which is very different from the concept of "face" in the past. In as much as the Chinese of today lives and works in a variety of worlds, it is also true to suggest that the core values which have defined this culture for centuries have also started to take on a new western and global sheen - less intuitive, less emotional, and more rational, cognitive and "applied” to situations and contexts. 